\title{
Sun-light-driven Suzuki-Miyaura Cross-coupling using a Novel Superparamagnetic Metal-organic Framework Catalyst
}

\author{
Sina Taraghi, ${ }^{1}$ (1) Batool Akhlaghinia, ${ }^{1, *}$ (1) Ali Reza Pourali ${ }^{2}$
}

\author{
1 Department of Chemistry, Faculty of Science, Ferdowsi University of Mashhad, Mashhad 9177948974, Iran \\ 2 School of Chemistry, Damghan University, Damghan 36715-364, Iran \\ * Corresponding author's e-mail address: akhlaghinia@um.ac.ir \\ RECEIVED: January 16, 2021 * REVISED: February 20, 2021 * ACCEPTED: February 21, 2021
}

\begin{abstract}
A prominent catalytic activity for sun-light driven Suzuki-Miyaura cross-coupling reaction has been shown in the presence of superparamagnetic core-shell metal-organic framework ( $\mathrm{Fe}_{3} \mathrm{O}_{4} @ \mathrm{Ni}-\mathrm{Co}-\mathrm{BTC} \mathrm{NPs}$ ) (with particle size 10-47 nm) and unique bimetallic core-shell nanostructure). Various aryl halides with electron-donating or electron-withdrawing substituents were coupled with different arylboronic acids towards corresponding products at ambient temperature in $\mathrm{H}_{2} \mathrm{O}$. The results of photocatalysis demonstrate that $\mathrm{Fe}_{3} \mathrm{O}_{4} @ \mathrm{Ni}-\mathrm{Co}-\mathrm{BTC}$ NPs is a good photocatalyst under sun light irradiation with high efficiency, chemoselectivity and functional group tolerance. This magnetic separable nanostructured catalyst can be reused more than six times with minimal loss of catalytic activity rendering this catalyst long-term stability. The results acquired in the present study can serve as inspiration for the further exploitation of the sun-light-driven cross-coupling reaction under mild conditions.
\end{abstract}

Keywords: superparamagnetic core-shell metal-organic framework $\left(\mathrm{Fe}_{3} \mathrm{O}_{4} @ \mathrm{Ni}-\mathrm{Co}-\mathrm{BTC} \mathrm{NPs}\right)$, Suzuki-Miyaura cross coupling reaction, photocatalysis, aryl halides, arylboronic acid, sun-light-driven reaction.

\section{INTRODUCTION}

$\mathrm{N}$ modern organic synthesis, Suzuki-Miyaura cross coupling reaction (as one-step pathway) has become arguably the most crucial and fundamental transformation for carbon-carbon bond formation to achieve synthetic building blocks of various natural products and biologically important compounds. ${ }^{[1-6]}$ Traditionally, the Suzuki-Miyaura cross-coupling reaction was typically realized mainly using homogeneous or heterogeneous transition metal ( $\mathrm{Pd},{ }^{17-21]}$ $\left.\mathrm{Ni},{ }^{22,23]} \mathrm{Co},{ }^{[22,24]} \mathrm{Cu}^{[22,25,26]} \mathrm{Fe}^{[22,27]}\right)$ catalytic systems. Nonetheless, the reported processes require relatively high reaction temperature to overcome the activation energy barrier of redox processes (electron transfer step between transition-metal catalysts and organic substances) in C-C coupling reaction. Elevated temperature may reduce the accessible active sites on the solid supports (for the reactants) via the aggregation of metal nanoparticles dispersed on solid supports which damages the recyclability of the catalysts. ${ }^{[28,29]}$ To facilitate the redox cycle, visible light or more preferably natural sunlight as a clean, abundant, and sustainable source of energy, can be utilized to furnish the $\mathrm{C}-\mathrm{C}$ cross-coupling reaction in the presence of photocatalyst at room temperature. ${ }^{[30-39]}$ Photocatalysts can convert light energy existing in nature into the required energy for $\mathrm{C}-\mathrm{C}$ cross-coupling reaction (the photoexcited electrons transfer to substances for initiating C-C coupling reactions). With the development of photocatalytic technology, lightdriven chemical reactions has been attracting much attention as a crucial way to follow environmentally benign, green synthetic and sustainable processes. ${ }^{[40-45]}$ In this direction, although a variety of photocatalytic systems have been developed to carry out $\mathrm{C}-\mathrm{C}$ coupling reactions, studies into visible-light-driven $\mathrm{C}-\mathrm{C}$ coupling reactions is still considered as an important objective for Suzuki-Miyaura cross coupling reaction. ${ }^{[46-55]}$ We have been particularly interested in using photocatalyst as a new mean to drive chemical transformations under ambient conditions, with high activity and selectivity. As a part of our ongoing work towards the development of efficient green catalysts, ${ }^{[56,57]}$ very recently,

(cc) Br 
we have reported $\mathrm{Fe}_{3} \mathrm{O}_{4} @ \mathrm{Ni}-\mathrm{Co}-\mathrm{BTC}$ NPs as a highly photoactive magnetic core-shell metal organic framework catalyst for aerobic oxidation of alcohols in green media (water), under base-free conditions and solar light irradiation (Scheme 1). ${ }^{[58]}$ In the present study, we aim to utilize $\mathrm{Fe}_{3} \mathrm{O}_{4} @ \mathrm{Ni}-\mathrm{Co}-\mathrm{BTC}$ NPs in Suzuki-Miyaura cross coupling reaction with visible light at ambient temperature (Scheme 2).

\section{EXPERIMENTAL}

\section{General}

All the chemical reagents and solvents were purchased from Merck chemical company and were used as received without any further purification. The purity determination of the products and reaction progress were obtained by TLC on silica gel polygram STL G/UV 254 plates. The melting points of the products were determined with an Electrothermal Type 9100 melting point apparatus. The FT-IR spectra were recorded on an AVATAR $370 \mathrm{FT}$-IR spectrometer (Therma Nicolet spectrometer, USA) using $\mathrm{KBr}$ plates at room temperature in the range between 4000 and $400 \mathrm{~cm}^{-1}$ with a resolution of $4 \mathrm{~cm}^{-1}$. The NMR spectra were recorded on a Bruker Avance 300 and $400 \mathrm{MHz}$ instrument in $\mathrm{CDCl}_{3}$ as

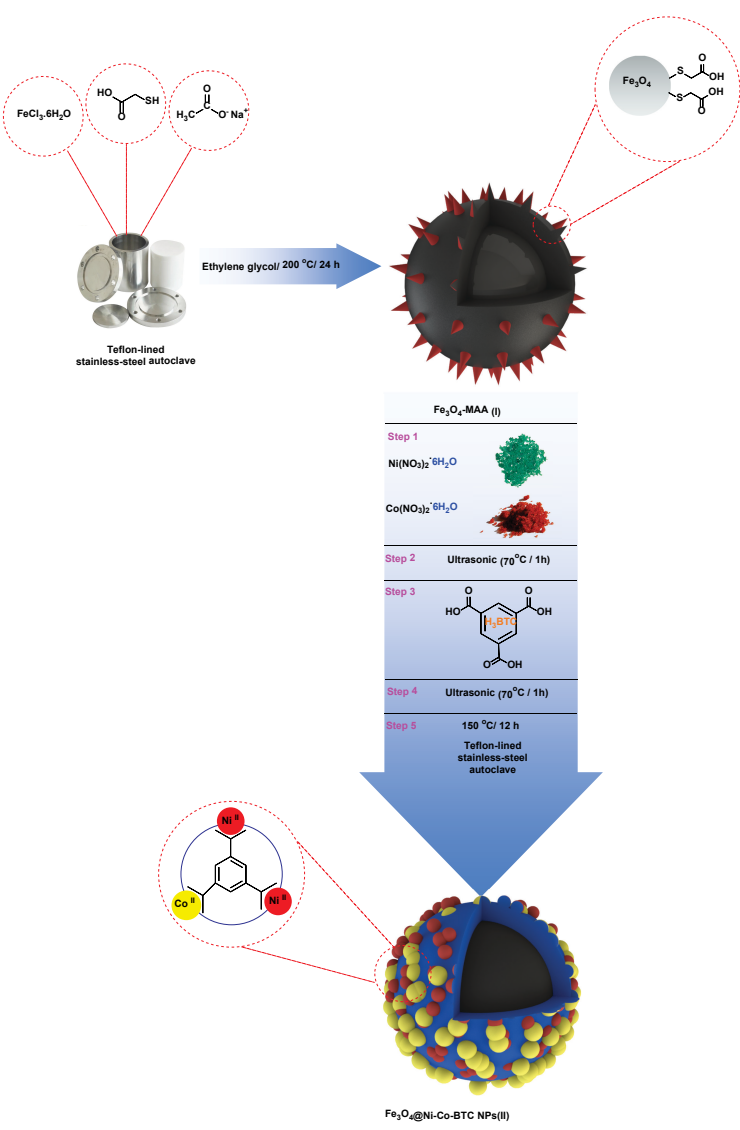

Scheme 1. Synthetic route to $\mathrm{Fe}_{3} \mathrm{O}_{4} @ \mathrm{Ni}-\mathrm{Co}-\mathrm{BTC}$ NPs (II). the solvent. Mass spectra were recorded with a $\mathrm{CH} 7 \mathrm{~A}$ Varianmat Bremen instrument at $70 \mathrm{eV}$ electron impact ionization, in $m / z$ (rel. \%). UV-vis. diffuse reflectance (DRS) spectra were obtained in air at room temperature in the 200-800 nm wavelengths range by means of a Shimadzu UV-2550 instrument (Japan). Inductively coupled plasma optical emission spectroscopy (ICP-OES) was carried out on a 76004555 SPECTRO ARCOS ICP-OES analyzer. Core-shell metal-organic framework ( $\mathrm{Fe}_{3} \mathrm{O}_{4} @ \mathrm{Ni}$-Co-BTC NPs) was prepared by the method reported in the literature. ${ }^{[58]}$ All the yields refer to the isolated products after purification by thin-layer chromatography /or column chromatography.

\section{Typical procedure for the sun-light-driven Suzuki-Miyaura cross-coupling reaction in the presence of $\mathrm{Fe}_{3} \mathrm{O}_{4} @ \mathrm{Ni}$-Co-BTC NPs}

A beaker glassware was charged by a mixture of iodobenzene $(1 \mathrm{mmol}, 0.203 \mathrm{~g})$, phenylboronic acid $(1 \mathrm{mmol}, 0.121 \mathrm{~g})$ and $\mathrm{KOH}(4 \mathrm{mmol}, 0.224 \mathrm{~g})$ in water at ambient temperature. $\mathrm{Fe}_{3} \mathrm{O}_{4} @ \mathrm{Ni}-\mathrm{Co}-\mathrm{BTC}$ NPs (II) (0.03 g, $9.6 \mathrm{~mol} \% \mathrm{Ni}$ : $4.47 \mathrm{~mol} \%$ $\mathrm{Co}$ ) was then added to the resulting mixture under stirring. The beaker glassware was then placed under the outdoor solar light irradiation between 8 am to $3 \mathrm{pm}$ (July to August 2019 , in daily ambient temperature $\left(37-39^{\circ} \mathrm{C}\right)$ ). After completion of the reaction $(5 \mathrm{~h})$ which was monitored by TLC, the nanostructured catalyst was separated using an external magnetic field, washed with ethanol three times and dried in an oven at $60^{\circ} \mathrm{C}$ overnight. The reaction mixture was then extracted with ethyl acetate $(5 \times 5 \mathrm{~mL})$ and the

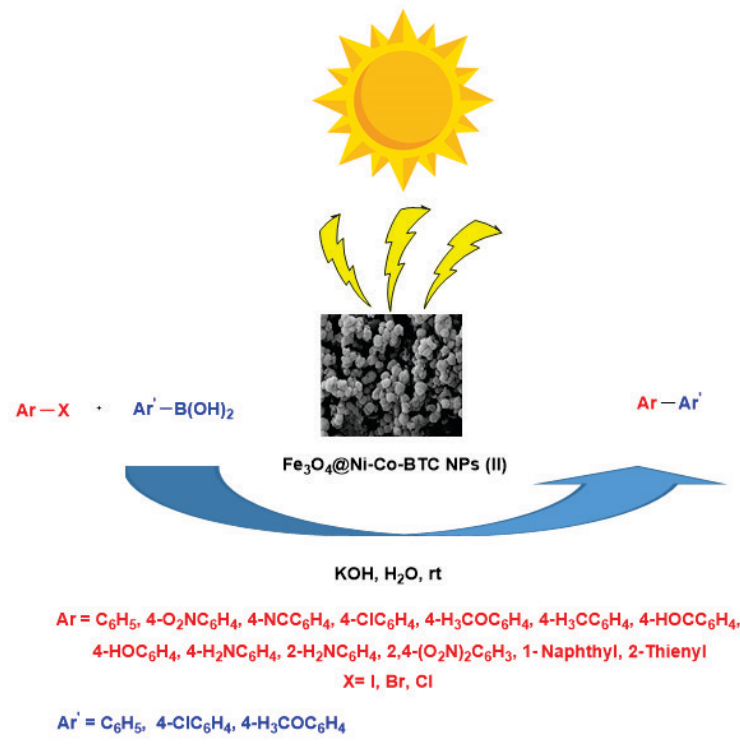

Scheme 2. Sun-light-driven Suzuki-Miyaura cross-coupling reaction of aryl halides and aryl boronic acids catalyzed by $\mathrm{Fe}_{3} \mathrm{O}_{4} @ \mathrm{Ni}-\mathrm{Co}-\mathrm{BTC}$ NPs (II) 
combined organic layer was dried over anhydrous $\mathrm{Na}_{2} \mathrm{SO}_{4}$. After evaporation of the solvent, the crude product was purified by thin layer chromatography using $n$-hexane / ethyl acetate $(8: 2)$ or column chromatography using $n$-hexane / ethyl acetate $(50: 1)$ to produce the pure biphenyl $(0.145 \mathrm{~g}$, $95 \%$ yield).

\section{RESULTS AND DISCUSSION}

\section{Sun-Light-Driven Suzuki-Miyaura Cross-Coupling Reaction in the Presence of $\mathrm{Fe}_{3} \mathrm{O}_{4} @ \mathrm{Ni}$-Co-BTC Nps (II)}

At the outset of our investigation, we considered iodobenzene and phenylboronic acid as the model reactants for the sun-light-driven Suzuki-Miyaura cross-coupling reaction at ambient temperature $\left(37-39^{\circ} \mathrm{C}\right)$ with a water bath to exclude the possibility of photothermal effects. To ascertain optimal reaction conditions, a range of reaction parameters (including the nature of the base and its concentration, the solvent, the catalyst loading, as well as the stoichometric ratio between iodobenzene and phenylboronic) were assessed. As this catalytic system is not sensitive to oxygen, the reactions were carried out under air atmosphere. The optimization of the process has been described in detail in Table $1 . \mathrm{H}_{2} \mathrm{O}$ was first chosen as the solvent for the sunlight-driven model reaction. As the presence of base is essential to activate phenyl boronic acid via enhancing the polarization of the organic ligand and thus facilitating transmetallation, the reaction does not proceed without any base. (Table 1 , entries 1,2 ) ${ }^{[3]}$ The $\mathrm{Fe}_{3} \mathrm{O}_{4} @ \mathrm{Ni}$-Co-BTC NPs (II) exhibited excellent photocatalytic activity while the reaction did not occur without any catalyst under irradiation, indicating the key catalytic role of $\mathrm{Fe}_{3} \mathrm{O}_{4} @ \mathrm{Ni}-\mathrm{Co}-\mathrm{BTC}$ NPs (II) for driving the Suzuki-Miyaura cross-coupling reaction (Table 1, entries 3, 4). To compare the efficiency of the conversions under different conditions, all reactions were stopped after $5 \mathrm{~h}$ and the reaction mixtures were analyzed. A variety of bases were investigated among which, $\mathrm{KOH}$ afforded the highest yield of biphenyl product under the given conditions (Table 1, entries 4-13). In contrast, $\mathrm{K}_{2} \mathrm{CO}_{3}$, TETA, $\mathrm{Li}_{2} \mathrm{CO}_{3}, \mathrm{NaHCO}_{3}, \mathrm{~K}_{3} \mathrm{PO}_{4}, \mathrm{NaOH}, \mathrm{WEB}, \mathrm{NH}_{4} \mathrm{OH}$, and NEt gave the biphenyl product in yields of $20 \%, 30 \%, 40 \%, 30$ $\%, 50 \%, 40 \%$, trace amounts, $40 \%$ and trace amounts, respectively. Further, we planned to carry out the model reaction in $\mathrm{a}_{2} \mathrm{O} / \mathrm{EtOH}(1: 1)$ solvent mixture and solventfree conditions under sun light irradiation (Table 1, entries $14,15)$. The highest yield of the target product was obtained in $\mathrm{H}_{2} \mathrm{O}$ (Table 1 , entry 4). Next, we surveyed different amounts of base and catalyst loading in sun-lightdriven model reaction. According to entries 16-23, it can be revealed that the highest yield was obtained when $1 / 4$ molar ratio of iodobenzene/base was treated with phenylboronic acid in the presence of $9.6 / 4.47 \mathrm{~mol} \%$ ratio of $\mathrm{Ni} / \mathrm{Co}$ (Table 1, entry 22). Afterwards, we screened the effect of applying 1/1.2 molar ratio of iodibenzene /phenylboronic acid on reaction rate (Table 1 , entry 24). No significant enhancement of catalytic activity was observed on sun-light-driven Suzuki-Miyaura cross-coupling reaction.

Noticeably, without irradiation (dark reaction), the reaction did not proceed to furnish the desired product indicating the significant contribution of irradiation on the catalytic activity of $\mathrm{Fe}_{3} \mathrm{O}_{4} @ \mathrm{Ni}-\mathrm{Co}-\mathrm{BTC}$ NPs (II) (Table 1, entry 25). To investigate the effect of $\mathrm{Fe}_{3} \mathrm{O}_{4} @ \mathrm{Ni}-\mathrm{Co}-\mathrm{BTC}$ NPs (II) photocatalyst composition, the coupling of iodobenzene with phenylboronic acid was conducted in the presence of $\mathrm{Fe}_{3} \mathrm{O}_{4} @ M A A N P s(\mathrm{I}), \mathrm{Fe}_{3} \mathrm{O}_{4} @ \mathrm{Ni}-\mathrm{BTC} \mathrm{NPs}$, and $\mathrm{Fe}_{3} \mathrm{O}_{4} @ \mathrm{Co}$-BTC NPs under sun-light irradiation (Table 1, entries 26-28). No biaryl product was detected after reacting for $24 \mathrm{~h}$ using $\mathrm{Fe}_{3} \mathrm{O}_{4} @ M A A N P s(\mathrm{I})$. Comparatively, the reaction in the presence of $\mathrm{Fe}_{3} \mathrm{O}_{4} @ \mathrm{Ni}-\mathrm{BTC}$ NPs and $\mathrm{Fe}_{3} \mathrm{O}_{4} @ \mathrm{Co}-\mathrm{BTC}$ NPs was sluggish and gained lower yield of desired product. To explore the photocatalytic activity of $\mathrm{Fe}_{3} \mathrm{O}_{4} @ \mathrm{Ni}-\mathrm{BTC} \mathrm{NPs}, \mathrm{Fe}_{3} \mathrm{O}_{4} @ \mathrm{Co}-\mathrm{BTC}$ NPs and $\mathrm{Fe}_{3} \mathrm{O}_{4} @ \mathrm{Ni}-\mathrm{Co}-$ BTC NPs (II), UV-vis. DRS analysis was performed and its results which discussed previously, ${ }^{[58]}$ are shown in Fig. 1. The band gap energies of $\mathrm{Fe}_{3} \mathrm{O}_{4} @ \mathrm{Ni}-\mathrm{BTC} \mathrm{NPs}, \mathrm{Fe}_{3} \mathrm{O}_{4} @ \mathrm{Co}-$ BTC NPs and $\mathrm{Fe}_{3} \mathrm{O}_{4} @ \mathrm{Ni}-\mathrm{Co}-\mathrm{BTC}$ NPs (II), calculated by the Kubelka-Munke equation were estimated to be 2.5, 3.2 and $2.3 \mathrm{eV}$ respectively. According to the obtained results, it could be concluded that higher photocatalytic activity of $\mathrm{Fe}_{3} \mathrm{O}_{4} @ \mathrm{Ni}-\mathrm{Co}-\mathrm{BTC} \mathrm{NPs}$ (II) in comparison to $\mathrm{Fe}_{3} \mathrm{O}_{4} @ \mathrm{Ni}-\mathrm{BTC}$ NPs and $\mathrm{Fe}_{3} \mathrm{O}_{4} @$ Co-BTC NPs could be related to its calculated band gap energy $(2.3 \mathrm{eV})$. Moreover, due to high band gap of $\mathrm{Fe}_{3} \mathrm{O}_{4} @ \mathrm{Co}-\mathrm{BTC}$ NPs (3.2 eV), high energy (such as UV light) is necessary to activate it. As sunlight contains low percentage of UV light ( 14\%), $\mathrm{Fe}_{3} \mathrm{O}_{4} @$ Co-BTC NPs exhibit lower photocatalytic activity under sun light irradiation.

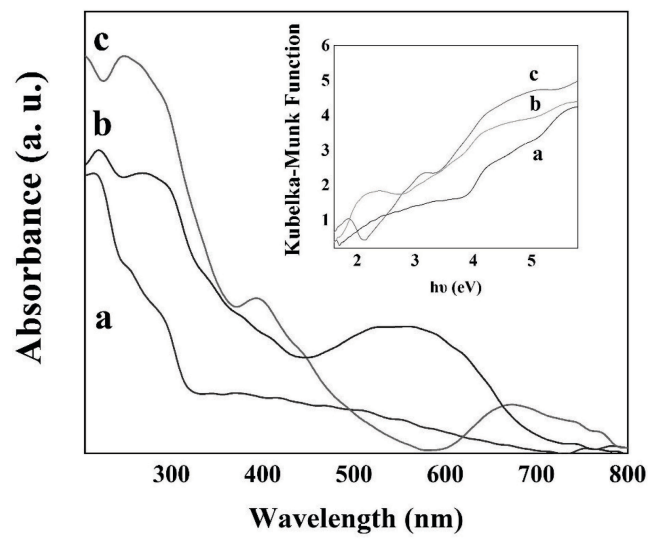

Figure 1. UV-vis. DRS spectra and Kubelka-Munke function (inset) of $\mathrm{Fe}_{3} \mathrm{O}_{4} @ \mathrm{Co}-\mathrm{BTC}$ NPs (a), $\mathrm{Fe}_{3} \mathrm{O}_{4} @ \mathrm{Ni}-\mathrm{Co}-\mathrm{BTC}$ NPs (II) (b) and $\mathrm{Fe}_{3} \mathrm{O}_{4} @ \mathrm{Ni}-\mathrm{BTC} N \mathrm{NP}$ (c). 
Table 1. Optimization of the reaction conditions for sun-light-driven Suzuki-Miyaura cross-coupling reaction of iodobenzene and phenylbronic acid. (a)

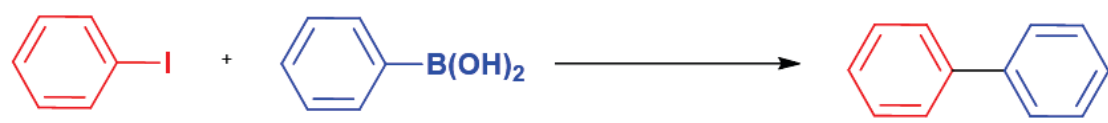

\begin{tabular}{|c|c|c|c|c|c|c|}
\hline Entry & $\begin{array}{c}\text { Catalyst }(\mathrm{mol} \% \text { ratio of } \\
\mathrm{Ni} / \mathrm{Co})^{(\mathrm{b})}\end{array}$ & $\begin{array}{c}\text { Molar ratio of } \\
\text { iodobenzene/base }\end{array}$ & Base & Solvent & Time / h & Isolated Yield / \% \\
\hline 1 & - & $1 / 0$ & - & $\mathrm{H}_{2} \mathrm{O}$ & 24 & - \\
\hline 2 & $6.4 / 2.98$ & $1 / 0$ & - & $\mathrm{H}_{2} \mathrm{O}$ & 24 & - \\
\hline 3 & - & $1 / 3$ & $\mathrm{KOH}$ & $\mathrm{H}_{2} \mathrm{O}$ & 24 & - \\
\hline 4 & $6.4 / 2.98$ & $1 / 3$ & $\mathrm{KOH}$ & $\mathrm{H}_{2} \mathrm{O}$ & 5 & 70 \\
\hline 5 & $6.4 / 2.98$ & $1 / 3$ & $\mathrm{~K}_{2} \mathrm{CO}_{3}$ & $\mathrm{H}_{2} \mathrm{O}$ & 5 & 20 \\
\hline 6 & $6.4 / 2.98$ & $1 / 3$ & $\operatorname{TETA}^{(c)}$ & $\mathrm{H}_{2} \mathrm{O}$ & 5 & 30 \\
\hline 7 & 6.4 / 2.98 & $1 / 3$ & $\mathrm{Li}_{2} \mathrm{CO}_{3}$ & $\mathrm{H}_{2} \mathrm{O}$ & 5 & 40 \\
\hline 8 & $6.4 / 2.98$ & $1 / 3$ & $\mathrm{NaHCO}_{3}$ & $\mathrm{H}_{2} \mathrm{O}$ & 5 & 30 \\
\hline 9 & $6.4 / 2.98$ & $1 / 3$ & $\mathrm{~K}_{3} \mathrm{PO}_{4}$ & $\mathrm{H}_{2} \mathrm{O}$ & 5 & 50 \\
\hline 10 & $6.4 / 2.98$ & $1 / 3$ & $\mathrm{NaOH}$ & $\mathrm{H}_{2} \mathrm{O}$ & 3 & 40 \\
\hline 11 & $6.4 / 2.98$ & $1 / 3$ & $W E B^{(d)}$ & $\mathrm{H}_{2} \mathrm{O}$ & 4 & Trace \\
\hline 12 & $6.4 / 2.98$ & $1 / 3$ & $\mathrm{NH}_{4} \mathrm{OH}$ & $\mathrm{H}_{2} \mathrm{O}$ & 3 & 40 \\
\hline 13 & $6.4 / 2.98$ & $1 / 3$ & $\mathrm{NEt}_{3}$ & $\mathrm{H}_{2} \mathrm{O}$ & 4 & Trace \\
\hline 14 & $6.4 / 2.98$ & $1 / 3$ & $\mathrm{KOH}$ & $\mathrm{H}_{2} \mathrm{O} / \mathrm{EtOH}(1: 1)$ & $3 / 5$ & $50 / 50$ \\
\hline 15 & 6.4 / 2.98 & $1 / 3$ & $\mathrm{KOH}$ & - & $3 / 5$ & $40 / 40$ \\
\hline 16 & $6.4 / 2.98$ & $1 / 2$ & $\mathrm{KOH}$ & $\mathrm{H}_{2} \mathrm{O}$ & 5 & 60 \\
\hline 17 & $6.4 / 2.98$ & $1 / 4$ & $\mathrm{KOH}$ & $\mathrm{H}_{2} \mathrm{O}$ & 5 & 80 \\
\hline 18 & $6.4 / 2.98$ & $1 / 5$ & $\mathrm{KOH}$ & $\mathrm{H}_{2} \mathrm{O}$ & 5 & 80 \\
\hline 19 & $1.6 / 0.74$ & $1 / 4$ & $\mathrm{KOH}$ & $\mathrm{H}_{2} \mathrm{O}$ & 5 & 40 \\
\hline 20 & $3.2 / 1.49$ & $1 / 4$ & $\mathrm{KOH}$ & $\mathrm{H}_{2} \mathrm{O}$ & 5 & 60 \\
\hline 21 & $8 / 3.72$ & $1 / 4$ & $\mathrm{KOH}$ & $\mathrm{H}_{2} \mathrm{O}$ & 5 & 90 \\
\hline 22 & $9.6 / 4.47$ & $1 / 4$ & $\mathrm{KOH}$ & $\mathrm{H}_{2} \mathrm{O}$ & 5 & 95 \\
\hline 23 & $12.8 / 5.96$ & $1 / 4$ & $\mathrm{KOH}$ & $\mathrm{H}_{2} \mathrm{O}$ & 5 & 95 \\
\hline $24^{(e)}$ & $9.6 / 4.47$ & $1 / 4$ & $\mathrm{KOH}$ & $\mathrm{H}_{2} \mathrm{O}$ & 5 & 95 \\
\hline $25^{(f)}$ & $9.6 / 4.47$ & $1 / 4$ & $\mathrm{KOH}$ & $\mathrm{H}_{2} \mathrm{O}$ & 6 & 20 \\
\hline $26^{(\mathrm{g})}$ & 0.03 & $1 / 4$ & $\mathrm{KOH}$ & $\mathrm{H}_{2} \mathrm{O}$ & $5 / 24$ & - \\
\hline $27^{(h)}$ & 9.6 & $1 / 4$ & $\mathrm{KOH}$ & $\mathrm{H}_{2} \mathrm{O}$ & 5 & 70 \\
\hline $28^{(i)}$ & 4.47 & $1 / 4$ & $\mathrm{KOH}$ & $\mathrm{H}_{2} \mathrm{O}$ & 5 & 60 \\
\hline
\end{tabular}

(a) All reactions were performed by using $1 / 1$ molar ratio of iodobenzene/phenylbronic acid at ambient temperature $\left(37-39^{\circ} \mathrm{C}\right)$ and solar light irradiation.

(b) The mol\% result was obtained from ICP-OES analysis.

(c) TETA: Triethylenetetramine.

(d) WEB: Water extract of banana

(e) The reaction was performed by using $1 / 1.2$ molar ratio of iodobenzene/phenylbronic acid.

(f) The reaction was performed in dark.

(g) Reaction was performed in the presence of $\mathrm{Fe}_{3} \mathrm{O}_{4} @ M A A N P s(\mathrm{I})$.

(h) Reaction was performed in the presence of $\mathrm{Fe}_{3} \mathrm{O}_{4} @ \mathrm{Ni}-\mathrm{BTC}$ NPs.

(i) Reaction was performed in the presence of $\mathrm{Fe}_{3} \mathrm{O}_{4} @ \mathrm{Co}-\mathrm{BTC}$ NPs. 
On the basis of the optimized reaction conditions (Table 1, entry 22), we then determined the scope and limitations of the sun-light-driven Suzuki-Miyaura cross-coupling reaction of a series of differently substituted aryl halides $(\mathrm{Cl}, \mathrm{Br}$ and $\mathrm{I})$ with different arylboronic acids in the presence of $\mathrm{Fe}_{3} \mathrm{O}_{4} @ \mathrm{Ni}-\mathrm{Co}-\mathrm{BTC}$ NPs (II) (Table 2). The yield and conversion time of the sun-light-driven SuzukiMiyaura cross-coupling reaction depend on the type of the aryl halides, the positions and electron-donating or electron-withdrawing nature of the substituents on the reactants. In comparison, aryl chlorides show little reactivity and lower conversion than similar aryl bromides and aryl iodides (Table 2, entries 13 and 15 vs. entries 8, 9 and entries 1 and 3). As illustrated in Table 2, electron-poor aryl halides (Table 2, entries 2-4, 9 and 14, 15) show higher reactivity than electron-rich ones (Table 2, entries 5, 6, 10 and 17-19). Moreover, due to steric hindrance ortho- substituted aryl halide shows poor reactivity than $p$-substituted one (Table 2 , entry 18 vs. entry 19). Furtheremore, to evaluate the selectivity of the catalyst in the sun-lightdriven Suzuki-Miyaura cross-coupling reaction, the competing reactions of aryl iodide and aryl chloride were studied using the dihalogenated aryl derivative as substrate (Table 2, entry 4). According to the obtained result (Table 2, entry 4), the conclusion could be derived that the aforesaid nanostructured catalyst catalyzed the sun-light-driven Suzuki-Miyaura cross-coupling reaction in a chemoselective manner. Driven by the above results, we then tried to extend the catalytic scope and generality of sun-lightdriven Suzuki-Miyaura cross-coupling reaction system towards various aryl boronic acids at the same reaction conditions. As shown in Table 2, aryl boronic acids with electron-releasing and electron-withdrawing substituents smoothly react with aryl halides to form the corresponding coupling products in excellent yields (Table 2, entries 20-25). Comparatively, the electron-rich aryl boronic acids reacted faster than those with electron-poor aromatic rings (Table 2, entries 20 vs. 23,21 vs. 24 and 22 vs. 25). Finally, to show the merit of the current protocol in the generality and versatility substrate scope, 2-bromothiophene as a heteroaryl halide and 2-bromonaphthalene as a model of sterically hindered aryl halide were efficiently reacted with phenyl boronic acid to give the corresponding cross coupled products under the same reaction conditions (Table 2, entries 11, 12).

All the cross-coupled products were known and isolated and purified by thin-layer chromatography or column chromatography as solid products. The obtained products were initially identified in detail by comparison of their melting points as well as mass spectra with those reported previously or with authentic samples. In addition, the structures of some selected products were effectively corroborated by surveying their FT-IR, high- field ${ }^{1} \mathrm{H}$ NMR and ${ }^{13} \mathrm{C}$ NMR spectral data (see Supporting Information file).

To postulate a suitable mechanism for the sun-lightdriven Suzuki-Miyaura cross coupling reaction, a series of control experiments were performed. To this end, the model optimized reaction (reaction between iodobenzene and phenyl boronic acid) was carried out in the presence of a hole scavenger (triethanolamine (TEOA)) and radicaltrapping agent (benzoquinone (BQ)). Before the quenching experiments, we first examined the possibility of processing reaction in the absence of light source to confirm the role of electron-hole pairs. As illustrated in Table 1 (entry 25), performing the reaction in the absence of light source leads to the desired product in $20 \%$ yield. It can be concluded that light has an essential role in this reaction. In the second step of our investigations, we turned our attention to study the reaction manner in the presence of scavengers. Upon light irradiation, hole-electron pairs can be generated via charge separation state (Scheme 3). When TEOA and $B Q$ were introduced separately into the reaction system, the obtained yields are almost the same as the dark conditions suggesting that photo-generated holes and radicals are completely quenched. These studies suggest that the photo-generated holes are essential for carrying out the Suzuki-Miyaura cross coupling reaction. Based on the above experiments result and according to the previous studies on the photo-catalyzed Suzuki-Miyaura cross coupling reaction, ${ }^{[53,59]}$ it is proposed that the mechanism initiated by attacking the photo-generated electrons to iodobenzene towards the cleavage of $\mathrm{C}-\mathrm{I}$ bond. In the meantime, the positive hole activates $C-B$ bond of phenyl boronic acid which is transferred into an electronically negative $\mathrm{B}(\mathrm{OH})_{3}{ }^{-}$species in basic media. The remaining step is consisting of reductive elimination and transmetalation which leads to the formation of the desired coupled product.

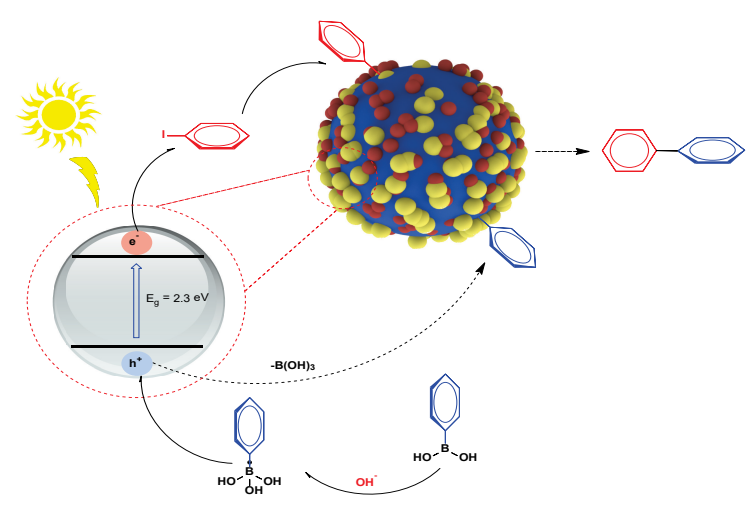

Scheme 3. Suggested reaction mechanism of the sun-lightdriven Suzuki-Miyaura cross-coupling reaction catalyzed by $\mathrm{Fe}_{3} \mathrm{O}_{4} @ \mathrm{Ni}-\mathrm{Co}-\mathrm{BTC}$ NPs (II). 
Table 2. The scope of sun-light-driven Suzuki-Miyaura cross-coupling reaction with different arylhalides and arylboronic acids catalyzed by $\mathrm{Fe}_{3} \mathrm{O}_{4} @ \mathrm{Ni}-\mathrm{Co}-\mathrm{BTC}$ NPs (II).

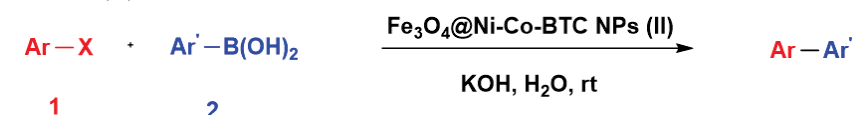

\begin{tabular}{|c|c|c|c|c|c|}
\hline Entry & 1 & 2 & Product & Time / h & Isolated Yield / \% \\
\hline 1 & & & & 5 & 95 \\
\hline 2 & & & & 5 & 85 \\
\hline 3 & & & & 6 & 80 \\
\hline 4 & & & & 6 & 75 \\
\hline 5 & & & & 8 & 40 \\
\hline 6 & & & & 8 & 50 \\
\hline 7 & & & & 6 & 30 \\
\hline 8 & & & & 6 & 85 \\
\hline 9 & & & & 6 & 75 \\
\hline 10 & & & & 6 & 45 \\
\hline 11 & & & & 6 & 70 \\
\hline 12 & & & & 6 & 55 \\
\hline 13 & & & & 7 & 60 \\
\hline 14 & & & & 7 & 20 \\
\hline 15 & & & & 7 & 55 \\
\hline 16 & & & & 7 & Trace \\
\hline 17 & & & & 7 & 30 \\
\hline 18 & & & & 7 & 30 \\
\hline
\end{tabular}




(2)

From both economic and environmental perspectives, the superiority of the heterogeneous catalysts lies in their lifetime and their level of reusability in the processes of the reactions and separation. To investigate the recyclability of $\mathrm{Fe}_{3} \mathrm{O}_{4} @ \mathrm{Ni}-\mathrm{Co}-\mathrm{BTC} \mathrm{NPs}$ (II), the sun-light-driven SuzukiMiyaura cross-coupling reaction of iodobenzene and phenylbronic acid was carried out in the presence of $\mathrm{Fe}_{3} \mathrm{O}_{4} @ \mathrm{Ni}$ Co-BTC NPs (II) as the catalyst in water as the sole solvent. After completion of each reaction run, the catalyst was separated using an external magnetic field, washed with ethanol three times and dried in an oven at $60{ }^{\circ} \mathrm{C}$ overnight. The above test reaction was performed again under the same conditions utilizing the recovered catalyst. Figure 2 demonstrates a slight loss of performance after six consecutive runs, suggesting excellent reusability and outstanding stability of $\mathrm{Fe}_{3} \mathrm{O}_{4} @ \mathrm{Ni}$-Co-BTC NPs (II) without noticeable deactivation. According to the obtained data from ICP-OES analysis, 1.49 and $1.48 \mathrm{mmol}$ of cobalt as well as 3.2 and $3.2 \mathrm{mmol}$ of nickel were anchored onto $1.000 \mathrm{~g}$ of fresh and sixth reused $\mathrm{Fe}_{3} \mathrm{O}_{4} @ \mathrm{Ni}-\mathrm{Co}-\mathrm{BTC} \mathrm{NPs}$ (II) respectively.

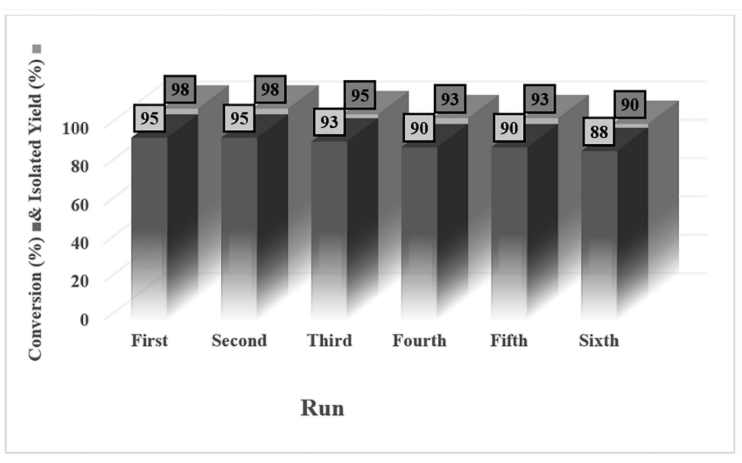

Figure 2. Reuse performance of $\mathrm{Fe}_{3} \mathrm{O}_{4} @ \mathrm{Ni}-\mathrm{Co}-\mathrm{BTC}$ NPs (II) in the sun-light-driven Suzuki-Miyaura cross-coupling reaction.
Here, to ascertain the stability of $\mathrm{Fe}_{3} \mathrm{O}_{4} @ \mathrm{Ni}$ - Co-BTC NPs (II), we employed FT-IR spectroscopy before and after the sun-light-driven Suzuki-Miyaura cross-coupling reaction (Figure 3). Figure $3 \mathrm{a}$ is identical to Figure $3 \mathrm{~b}$. We found that there are no changes in intensities, shapes and frequencies of absorption bands.

The catalytic activity of various photocatalysts in the literature was compared with $\mathrm{Fe}_{3} \mathrm{O}_{4} @ \mathrm{Ni}-\mathrm{Co}-\mathrm{BTC}$ NPs (II) in the Suzuki-Miyaura cross-coupling reaction of iodobenzene with phenylbronic acid as shown in Table 3. The comparison reveals that $\mathrm{Fe}_{3} \mathrm{O}_{4} @ \mathrm{Ni}$-Co-BTC NPs (II) catalyzed SuzukiMiyaura cross-coupling reaction under natural sun light irradiation without applying any other light sources (Table 3, entries 1-6 and entries 8-10). Also, compared with the other catalysts, $\mathrm{Fe}_{3} \mathrm{O}_{4} @ \mathrm{Ni}-\mathrm{Co}-\mathrm{BTC}$ NPs (II) can be easily separated by an external magnetic bar from the reaction mixture (Table 3 , entries 1-7 and entries 9,10 ) and showed high reusability as well (Table 3, entries 3-8 and entry10). The present methodology exhibits more efficiency in green media (Table 3 , entries 4, 5, 10) without using expensive Pd catalysts (Table 3, entries 1-7 and entries 9, 10).

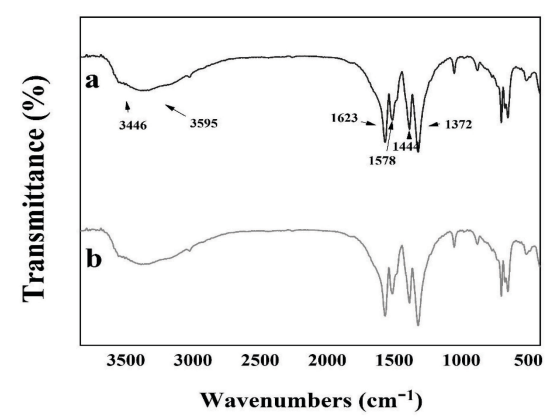

Figure 3. FT-IR spectra of $\mathrm{Fe}_{3} \mathrm{O}_{4} @ \mathrm{Ni}-\mathrm{Co}-\mathrm{BTC}$ NPs (II) (a) and the $6^{\text {th }}$ reused $\mathrm{Fe}_{3} \mathrm{O}_{4} @ \mathrm{Ni}-\mathrm{Co}-\mathrm{BTC}$ NPs (II) (b). 
Table 3. Comparison of various photocatalysts in the Suzuki-Miyaura cross-coupling reaction of iodobenzene with phenylbronic acid.

\begin{tabular}{|c|c|c|c|c|c|c|c|c|}
\hline Entry & Catalyst & Solvent & Light source & Temperature $/{ }^{\circ} \mathrm{C}$ & Time / h & Yield / \% & Reusability & Reference \\
\hline 1 & $\mathrm{Pd} / \mathrm{Au} / \mathrm{PN}^{(\mathrm{a})}-\mathrm{CeO}_{2}$ & $\mathrm{H}_{2} \mathrm{O}$ & Xe lamp & 25 & 0.5 & 98 & 6 & 46 \\
\hline 2 & $\mathrm{Pd} / \mathrm{rGO}$-doped g- $\mathrm{C}_{3} \mathrm{~N}_{4}$ & $\mathrm{EtOH} / \mathrm{H}_{2} \mathrm{O}$ & Xe lamp & 25 & $40 \mathrm{~min}$ & 98 & 6 & 55 \\
\hline 3 & $\mathrm{Pd}^{2+}-\mathrm{r}-\mathrm{GO}$ & $\mathrm{EtOH}$ & Xe lamp & 60 & 1 & 99.8 & - & 51 \\
\hline 4 & $\mathrm{Pd} @ P D A^{(b)}-C l$ & $\mathrm{DMF} / \mathrm{H}_{2} \mathrm{O}$ & White LED lamp & $\mathrm{rt}$ & 2 & 96 & - & 47 \\
\hline 5 & $\mathrm{Pd} @ \mathrm{~B}-\mathrm{BO}_{3}$ & $\mathrm{DMF} / \mathrm{H}_{2} \mathrm{O}$ & White LED lamp & $\mathrm{rt}$ & 2 & 98 & - & 49 \\
\hline 6 & $W_{2} / P d N P s$ & $\mathrm{EtOH} / \mathrm{H}_{2} \mathrm{O}$ & White LED lamp & $\mathrm{rt}$ & 4 & 98 & - & 52 \\
\hline 7 & $\mathrm{Pd}-\mathrm{MoS}_{2}$ nanosheets & $\mathrm{EtOH} / \mathrm{H}_{2} \mathrm{O}$ & Sunlight & $25 / 45$ & 2 & 97 & - & 50 \\
\hline 8 & $\mathrm{Fe}_{3} \mathrm{O}_{4} @ \mathrm{Cu}_{2-\mathrm{x}} \mathrm{S}-\mathrm{Fs}$ & EtOH & Xe lamp & 25 & 12 & 78 & - & 53 \\
\hline 9 & Nano Pd/ZnO & $\mathrm{H}_{2} \mathrm{O}$ & Visible light & rt & 1 & $>99$ & 5 & 54 \\
\hline 10 & Au-Pd alloy NP & $\mathrm{DMF} / \mathrm{H}_{2} \mathrm{O}$ & Visible light & 30 & 6 & 99 & - & 48 \\
\hline 11 & $\begin{array}{c}\mathrm{Fe}_{3} \mathrm{O}_{4} @ \mathrm{Ni}-\mathrm{Co}-\mathrm{BTC} \mathrm{NPs} \\
(\mathrm{II})\end{array}$ & $\mathrm{H}_{2} \mathrm{O}$ & Sunlight & $\mathrm{rt}$ & 5 & 95 & 6 & Present study \\
\hline
\end{tabular}

(a) PN: Porous nanorods.

(b) PDA: Polydopamine.

\section{CONCLUSION}

In conclusion, the previously designed and characterized $\mathrm{Fe}_{3} \mathrm{O}_{4} @ \mathrm{Ni}$-Co-BTC NPs (as a heterogeneous nanostructured catalyst with particle size $(10-47 \mathrm{~nm})$ and unique bimetallic core-shell nanostructure) efficiently activated aryl halides for Suzuki-Miyaura cross-coupling reaction under the sun light irradiation. So the sun-light-driven cross-coupling reaction proceeded in green solvent at room temperature with high chemoselectivity. The findings of the present study demonstrated the excellent photocatalytic performance of $\mathrm{Fe}_{3} \mathrm{O}_{4} @ \mathrm{Ni}$-Co-BTC NPs in the coupling of differently substituted aryl halides $(\mathrm{Cl}, \mathrm{Br}$ and $\mathrm{I})$ with different arylboronic acids under sustainable and mild process conditions. $\mathrm{Fe}_{3} \mathrm{O}_{4} @ \mathrm{Ni}-\mathrm{Co}-\mathrm{BTC}$ NPs shows excellent chemical and catalytic stability compared to the other catalysts considered in this study. Given the magnetic nature, the photocatalyst showed great potential to be separated very simple by means of an external magnetic field and reused six times with only a slight decrease in its catalytic activity. Such impressive catalytic activity, operational simplicity, mild reaction conditions, high product yield, and high reusability in addition to the utilization of sunlight as the energy source and environmental-friendly solvent are the notable advantages of the present procedure and make $\mathrm{Fe}_{3} \mathrm{O}_{4} @ \mathrm{Ni}$ Co-BTC NPs a significant green, sustainable, cost-efficient and industrially viable photocatalyst as well. It can be envisioned that this novel genre of photocatalyst could be applied to other classic cross coupling reactions and also, the present strategy can be used as a potential tool for the direct utilization of sunlight for attaining industrially crucial catalytic reactions that were happened under the restricted conditions previously.

Acknowledgment. The authors gratefully acknowledge the partial support of this study by Ferdowsi University of Mashhad Research Council (Grant No. p/3/51959).

Supplementary Information. Supporting information to the paper is attached to the electronic version of the article at: http://doi.org/10.5562/cca3741.

PDF files with attached documents are best viewed with Adobe Acrobat Reader which is free and can be downloaded from Adobe's web site.

\section{REFERENCES}

[1] N. Miyaura, A. Suzuki, J. Chem. Soc. Chem. Com. 1979, 866-867. https://doi.org/10.1039/c39790000866

[2] N. Miyaura, A. Suzuki, Chem. Rev. 1995, 95, 24572483. https://doi.org/10.1021/cr00039a007

[3] G. C. Fu, Acc. Chem. Res. 2008, 41, 1555-1564. https://doi.org/10.1021/ar800148f

[4] B. W. Glasspoole, C. M. Crudden, Nat. Chem. 2011, 3, 912-913. https://doi.org/10.1038/nchem.1210

[5] A. Fihri, M. Bouhrara, B. Nekoueishahraki, J. M. Basset, V. Polshettiwar, Chem. Soc. Rev. 2011, 40, 5181-5203. https://doi.org/10.1039/c1cs15079k

[6] A. Molnar, Chem. Rev. 2011, 111, 2251-2320. https://doi.org/10.1021/cr100355b

[7] N. Y. Baran, T. Baran, A. Menteş, Appl. Catal. A- Gen. 2017, 531, 36-44.

https://doi.org/10.1016/j.apcata.2016.12.005 
[8] Q. Fu, Y. Meng, Z. Fang, Q. Hu, L. Xu, W. Gao, X. Huang, Q. Xue, Y. P. Sun, F. Lu, ACS Appl. Mater. Interfaces 2017, 9, 2469-2476.

https://doi.org/10.1021/acsami.6b13570

[9] Y. Wang, C. Lu, G. Yang, Z. Chen, J. Nie, React. Funct. Polym. 2017,110, 38-46.

https://doi.org/10.1016/j.reactfunctpolym.2016.12.003

[10] S. Paul, M. M. Islam, S. M. Islam, RSC Adv. 2015, 5, 42193-42221.

https://doi.org/10.1039/C4RA17308B

[11] R. Ma, P. Yang, Y. Ma, F. Bian, ChemCatChem, 2018, 10, 1446-1454. https://doi.org/10.1002/cctc.201701693

[12] G. J. Lichtenegger, M. Maier, M. Hackl, J. G. Khinast, W. Gössler, T. Griesser, V. P. Kumar, H. GruberWölfler, P. A. Deshpande, J. Mol. Catal. A-Chem. 2017, 426, 39-51. https://doi.org/10.1016/j.molcata.2016.10.033

[13] S. Lebaschi, M. Hekmati and H. Veisi, J. Colloid Interface Sci. 2017, 485, 223-231. https://doi.org/10.1016/j.jcis.2016.09.027

[14] X. Le, Z. Dong, Y. Liu, Z. Jin, T. D. Huy, M. Le, J. Ma, J. Mater. Chem. A 2014, 2, 19696-19706. https://doi.org/10.1039/C4TA04919E

[15] R. R. Guerra, F. C. Martins, C. G. Lima, R. H. Gonçalves, E. R. Leite, E. R. Pereira-Filho, R. S. Schwab, Tetrahedron Lett. 2017, 58, 903-908. https://doi.org/10.1016/j.tetlet.2017.01.046

[16] T. Baran, J. Colloid Interface Sci. 2017, 496, 446-455. https://doi.org/10.1016/j.jcis.2017.02.047

[17] R. Jahanshahi, B. Akhlaghinia, Catal. Lett. 2017, 147, 2640-2655.

https://doi.org/10.1007/s10562-017-2170-x

[18] M. S. Ghasemzadeh, B. Akhlaghinia, Aust. J. Chem. 2019, 72, 674-692.

https://doi.org/10.1071/CH19117

[19] M. Zarghani, B. Akhlaghinia, Bull. Chem. Soc. Jpn. 2016, 89, 1192-1200.

https://doi.org/10.1246/bcsj.20160163

[20] N. Razavi, B. Akhlaghinia, R. Jahanshahi, Catal. Lett. 2017, 147, 360-373.

https://doi.org/10.1007/s10562-016-1944-x

[21] A. Elhampour, M. S. Mirhosseyni, F. Nemati, J. Chin. Chem. Soc. 2018, 65, 875-882.

https://doi.org/10.1002/jccs.201700341

[22] S. B. Tailor, M. Manzotti, S. Asghar, B. J. Rowsell, S. L. Luckham, H. A. Sparkes, R. B. Bedford, Organometallics 2019, 38, 1770-1777. https://doi.org/10.1021/acs.organomet.9b00083

[23] J. Xia, Y. Fu, G. He, X. Sun, X. Wang, Appl. Catal. BEnviron. 2017, 200, 39-46.

https://doi.org/10.1016/j.apcatb.2016.06.066
[24] A. Mohammadinezhad, B. Akhlaghinia, Green Chem. 2017, 19, 5625-5641. https://doi.org/10.1039/C7GC02647A

[25] S. Anuma, P. Mishra, B. R. Bhat, J. Taiwan Inst. Chem. Eng. 2019, 95, 643-651. https://doi.org/10.1016/j.jtice.2018.09.029

[26] R. M. Ansari, B. R. Bhat, Chem. Phys. 2019, 517, 155160.

https://doi.org/10.1016/j.chemphys.2018.09.018

[27] L. M. Kumar, P. Mishra, B. R. Bhat, J. Saudi Chem. Soc. 2019, 23, 307-314. https://doi.org/10.1016/j.jscs.2018.08.005

[28] (a) C. A. Fleckenstein, H. Plenio, Chem. Soc. Rev. 2010, 39, 694-711. https://doi.org/10.1039/B903646F

(b) L. M. Zhang, H. Y. Li, H. X. Li, D. J. Young, Y. Wang, J. P. Lang, Inorg. Chem. 2017, 56, 11230-11243. https://doi.org/10.1021/acs.inorgchem.7b01616

[29] A. Wittstock, V. Zielasek, J. Biener, C. M. Friend, M. Bäumer, Science 2010, 327, 319-322. https://doi.org/10.1126/science.1183591

[30] G. Palmisano, V. Augugliaro, M. Pagliaro, L. Palmisano Chem. Commun. 2007, 3425-3437. https://doi.org/10.1039/b700395c

[31] M. Fagnoni, D. Dondi, D. Ravelli, A. Albini Chem. Rev. 2007, 107, 2725-2756. https://doi.org/10.1021/cr068352x

[32] S. Navalon, R. Martin, M. Alvaro, H. Garcia, ChemSusChem 2011, 4, 650-657. https://doi.org/10.1002/cssc.201000453

[33] D. Cambié, F. Zhao, V. Hessel, M. G. Debije, T. Noël, Angew. Chem. 2017,129, 1070-1074. https://doi.org/10.1002/ange.201611101

[34] Z. Jiao, Z. Zhai, X. Guo, X. Y. Guo, J. Phys. Chem. C 2015, 119, 3238-3243. https://doi.org/10.1021/jp512567h

[35] F. Wang, C. Li, H. Chen, R. Jiang, L. D. Sun, Q. Li, J. Wang, J. C. Yu, C. H. Yan, J. Am. Chem. Soc. 2013, 135, 5588-5601. https://doi.org/10.1021/ja310501y

[36] N. Corrigan, S. Shanmugam, J. Xu, C. Boyer, Chem. Soc. Rev. 2016, 45, 6165-6212. https://doi.org/10.1039/C6CS00185H

[37] C. K. Prier, D. A. Rankic, D. W. MacMillan, Chem. Rev. 2013, 113, 5322-5363. https://doi.org/10.1021/cr300503r

[38] K. L. Skubi, T. R. Blum, T. P. Yoon, Chem. Rev. 2016, 116, 10035-10074. https://doi.org/10.1021/acs.chemrev.6b00018

[39] M. D. Karkas, J. A. Porco Jr., C. R. Stephenson, Chem. Rev. 2016, 116, 9683-9747. https://doi.org/10.1021/acs.chemrev.5b00760 
[40] J. C. Colmenares, R. Luque, Chem. Soc. Rev. 2014, 43, 765-778. https://doi.org/10.1039/C3CS60262A

[41] D. Wang, Z. Li, J. Catal. 2016, 342, 151-157. https://doi.org/10.1016/j.jcat.2016.07.021

[42] M. F. Gálvez-López, M. J. Muñoz-Batista, C. G. Alvarado-Beltrán, J. L. Almaral-Sánchez, B. BachillerBaeza, A. Kubacka, M. Fernández-García, Appl. Catal. B- Environ. 2018, 228, 130-141. https://doi.org/10.1016/j.apcatb.2018.01.075

[43] X. Hu, G. Zhang, F. Bu, A. Lei, Angew. Chem. 2018, 130, 1300-1304. https://doi.org/10.1002/ange.201711359

[44] G. Zhao, W. Zhou, Y. Sun, X. Wang, H. Liu, X. Meng, K. Chang, J. Ye, Appl. Catal. B- Environ. 2018, 226, 252-257. https://doi.org/10.1016/j.apcatb.2017.12.054

[45] X. H. Jiang, Q. J. Xing, X. B. Luo, F. Li, J. P. Zou, S.S. Liu, X. Li, X. K. Wang, Appl. Catal. B- Environ. 2018, 228, 29-38.

https://doi.org/10.1016/j.apcatb.2018.01.062

[46] S. Zhang, C. Chang, Z. Huang, Y. Ma, W. Gao, J. Li, Y. Qu ACS Catalysis 2015, 5 6481-6488. https://doi.org/10.1021/acscatal.5b01173

[47] A. Xie, K. Zhang, F. Wu, N. Wang, Y. Wang, M. Wang, Catal. Sci. Technol. 2016, 6 1764-1771. https://doi.org/10.1039/C5CY01330E

[48] Q. Xiao, S. Sarina, E. Jaatinen, J. Jia, D. P. Arnold, H. Liu, H. Zhu, Green Chem. 2014, 16, 4272-4285. https://doi.org/10.1039/C4GC00588K

[49] Z. J. Wang, S. Ghasimi, K. Landfester, K. A. Zhang, Chem. Mater. 2015, 27, 1921-1924. https://doi.org/10.1021/acs.chemmater.5b00516
[50] H. H. Shin, E. Kang, H. Park, T. Han, C. H. Lee, D. K. Lim, J. Mater. Chem. A 2017, 5, 24965-24971. https://doi.org/10.1039/C7TA08441B

[51] H. H. Shin, T. Han, W. Yang, D. K. Lim, Carbon 2019, 143, 362-370. https://doi.org/10.1016/j.carbon.2018.11.039

[52] F. Raza, D. Yim, J. H. Park, H. I. Kim, S. J. Jeon, J. H. Kim, J. Am. Chem. Soc. 2017, 139, 14767-14774. https://doi.org/10.1021/jacs.7b08619

[53] Y. Luo, Y. Peng, W. Liu, F. Chen, B. Wang, Chem. Eur. J. 2017, 23, 8879-8885. https://doi.org/10.1002/chem.201605794

[54] M. Hosseini-Sarvari, Z. Bazyar, ChemistrySelect 2018, 3, 1898-1907. https://doi.org/10.1002/slct.201702219

[55] K. Dânoun, Y. Essamlali, O. Amadine, R. Tabit, A. Fihri, C. Len, M. Zahouily, Appl. Organomet. Chem. 2018, 32, 4232-4241. https://doi.org/10.1002/aoc.4232

[56] M. S. Ghasemzadeh, B. Akhlaghinia, New J. Chem. 2019, 43, 5341-5356.

https://doi.org/10.1039/C9NJ00352E

[57] (a) N. Mohammadian, B. Akhlaghinia, Res. Chem. Intermed. 2019, 45, 4737-4756.

https://doi.org/10.1007/s11164-019-03860-x (b) H. Karimzadegan, B. Akhlaghinia, M. S. Ghasemzadeh, Iran. J. Catal. 2019, 9, 109-120.

[58] A. Mohammadinezhad, B. Akhlaghinia, Catal. Lett. 2021, 151,107-123. https://doi.org/10.1007/s10562-020-03291-z

[59] J. Chakraborty, I. Nath, F. Verpoort, Chem. Eng. J. 2019, 358, 580-588. https://doi.org/10.1016/j.cej.2018.09.037 